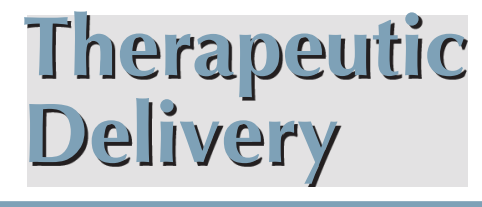

\title{
A model to integrate patient preferences into delivery systems: the importance of end-user input into pulmonary delivery
}

\author{
"To ensure that patients can actually use drug-delivery devices ... \\ future research needs to engage patients and caregivers early in the \\ device design process."
}

First draft submitted: 20 June 2016; Accepted for publication: 22 August 2016; Published online: 1 September 2016

Keywords: inhaler technique $\bullet$ inhaler design $\bullet$ patient preference

Asthma is a public health problem estimated to affect approximately 334 million people worldwide [1]. A significant amount of those affected with asthma are children [1]. Asthma is a chronic disease that is characterized by inflammation and constriction of the airways, leading to breathing difficulties. It is estimated that in the USA alone, the direct cost for asthma in both adults and children was more than $\$ 56$ billion annually in 2007 and is responsible for reduced quality of life [2]. Asthma cannot be cured, but it can be controlled by medication. The most common and efficacious medications to treat asthma are delivered in aerosol form via nebulizer inhaler devices, which include pressurized metered-dose inhalers and dry-powder inhalers (DPIs) [3]. Unlike many oral dosage forms, inhaler compliance is composed of two independent components, temporal adherence and inhaler technique, of which much research has focused on temporal adherence due to limited methods available to monitor longitudinally. For this reason, the aim of this editorial is to describe problems with inhaler technique from published literature as well as propose a new method of integrating patients into the therapeutic delivery research process to reduce patient error, which may improve asthma outcomes.

Many advances in inhalation drug delivery have improved drug efficacy, device efficiency and ease of use. Recent pharmaceutical research literature summarizing advances in pulmonary drug delivery highlights advances in device technology and formulations [4,5]. Traditionally, inhalation devices such as pressurized metered-dose inhalers and DPIs require patients to perform a series of steps correctly in the appropriate sequence to ensure proper delivery of the medication to its target organ, the lungs. Many devices are unique, each with varying number and sequence steps as well as flow rates necessary for optimal drug delivery. As such, researchers have recognized the need for user-friendly devices as a strategy to optimize aerosol delivery. Recent innovative respiratory drug-delivery strategies include flow independent powders, inhalation monitoring devices and acoustic monitoring devices for DPIs [6-8]. Further, GlaxoSmithKline conducted a clinical trial to explore patient preference in inhaler-specific attributes such as size of the numbers on the dose counter, number of steps needed, inhaler size, comfort of mouthpiece and ease of opening [9].

On the clinical research side, investigators evaluate a variety of factors that can facilitate or hinder a patient's ability to administer an inhaled drug. A recent systematic review of inhaler technique among children with asthma found that frequent educational interventions by healthcare practitioners and/or family members were associated with improved inhaler technique; however, this study also described how the majority of



Nicole Rockich-Winston ${ }^{* 1}$, Chris Gillette', Brian Train', Amber S Tippens', Susan Flesher $^{3}$ \& Meagan Shepherd ${ }^{3}$ ${ }^{1}$ Assistant Professor, Marshall University School of Pharmacy, 1 John Marshall Dr., Huntington, WV 25755, USA

${ }^{2}$ Assistant Professor, Wingate University School of Pharmacy, 515 Main St, Wingate, NC, 28147, USA ${ }^{3}$ Associate Professor, Marshall University Joan C. Edwards School of Medicine, Department of Pediatrics, Huntington, WV 25701, USA

*Author for correspondence:

Tel.: +1 3046967369

Fax: +1 3046967309

winstonn@marshall.edu 
the time children rarely use their inhalers correctly as prescribed by medical providers [10]. The review corroborates the most recent systematic review evaluating inhaler technique in adults that discusses how adults also rarely use their inhaler correctly [11]. Likewise, traditional methods to monitor inhaler technique have been limited to using subjective checklist method, leading to high inter-observer variability which also fails to assess real-world use patterns and inspiratory flow rates. These studies show that poor inhaler technique is a tremendous public health concern and is a worldwide phenomenon.

Previous research has found that $10-50 \%$ of inhaled drug is delivered to its target organ, the lungs, assuming perfect inhalation technique [3]. The results on inhaler technique in children found that at most 56\% of children had correct inhalation technique and as few as $8 \%$ of children had correct inhalation technique [10]. Another surprising finding of this work is a paucity of research has examined how child inhaler technique is associated with pulmonary outcomes. Other studies in adults found that at most $59 \%$ of adults use correct inhalation technique and this has not improved over the past 40 years [12]. Since drug deposition is dependent on inhalation technique, it is imperative to improve child inhaler technique so that the maximum amount of drug can be deposited into the child's lungs for symptom relief and prevention of future exacerbations. Scientists investigating new drug-delivery mechanisms need to be cognizant of the complexity of their devices as well as reduce their complexity as much as possible.

Only now has inhaler technique been recognized as an important piece of asthma control, due to increased availability of objective methods to longitudinally monitor inhaler technique [13,14]. Outside of clinical trials, very few healthcare providers, such as physicians, nurses and pharmacists, actually discuss how to properly use an inhalation device, of which providers have demonstrated deficiencies in inhaler technique as well [15-17]. As described above, the systematic review found that children were more likely to have better technique when they were instructed on how to use their inhalation device and with repeated education [10]. In fact, both the National Heart, Lung and Blood Institute's asthma practice guidelines and the Global Initiative for Asthma practice guidelines recommend that providers check inhaler technique at every opportunity and correct patients when mistakes are made [3,14]. In addition, there has been a recent call to initiate patientfriendly approach to inhaler selection, allowing the patient to decide what type of inhaler device feels most comfortable to improve patient compliance [18].

Despite the efforts led by both pharmaceutical researchers and clinicians to overcome inhaler technique deficiencies, inhalation drug delivery still faces an uphill battle in the drug discovery process. As with any new drug or drug delivery device, clinical trials serve as the testing point for the product-user interface. However, unlike in vivo studies or clinical trials, most patients who are prescribed inhalation devices do not receive continual instructions on device use from their healthcare provider in practice $[15,16]$. When both adults and children are expected to use a device, and as the literature suggests they are clearly ill-prepared to use, it is the responsibility of device researchers and manufacturers to develop devices that patients can use correctly on a regular basis. In addition, it is also the responsibility of the clinician to counsel and provide strategies to optimize inhaler device use.

We propose a new model tailored for drug-delivery devices that is similar to the research process currently conducted by the Patient-Centered Outcomes Research Institute (PCORI). PCORI is an independent, nonprofit, nongovernmental organization that funds comparative effectiveness research [19]. The mission of PCORI is to provide evidence-based information to improve healthcare delivery and outcomes. The evidence that is generated by PCORI-funded studies is guided by patients and their caregivers, which results in outcomes pertinent to patients. Studies funded by PCORI must include patients into the design and conduct of the study through dissemination of results. Analogous to the pragmatic, randomized control trial instituted by the Salford Lung Study [20], this funding organization requires researchers to examine outcomes that matter to patients with the disease.

To ensure that patients can actually use drug-delivery devices, such as inhalers, future research needs to engage patients and caregivers early in the device design process. This would allow end-users to provide feedback regarding the device, including ease of use, obstacles associated with the device, how they would use the device without any instruction, etc. so that investigators can incorporate this feedback into the initial design. Ensuring that the end-users of innovative drug-delivery devices can use the device correctly will ultimately help improve drug deposition and most importantly enhance clinical outcomes, such as disease control and health-related quality of life.

\section{Financial \& competing interests disclosure}

The authors have no relevant affiliations or financial involvement with any organization or entity with a financial interest in or financial conflict with the subject matter or materials discussed in the manuscript. This includes employment, consultancies, honoraria, stock ownership or options, expert testimony, grants or patents received or pending, or royalties.

No writing assistance was utilized in the production of this manuscript. 


\section{References}

Papers of special note have been highlighted as:

- of interest; $\bullet \bullet$ of considerable interest

1 The Global Asthma Report 2014. www.globalasthmareport. org/burden/burden.php.

2 Centers for Disease Control and Prevention. Asthma in the US. www.cdc.gov/vitalsigns/asthma/

3 National Heart, Lung, and Blood Institute. Guidelines for the diagnosis and management of asthma. www.nhlbi.nih. gov/files/docs/guidelines/asthgdln.pdf

4 Ibrahim M, Verma R, Garcia-Contreras L. Inhalation drug delivery devices: technology update. Med. Devices. 8 , 131-139 (2015).

5 Cipolla DC, Gonda I. Formulation technology to repurpose drugs for inhalation delivery. Drug Discov. Today Ther. Strateg. 8(3-4), 123-130 (2011)

6 Otake H, Okuda T, Hira D, Kojima H, Shimada Y, Okamoto H. Inhalable spray-freeze-dried powder with L-leucine that delivers particles independent of inspiratory flow pattern and inhalation device. Pharm. Res. 33, 922-931 (2016).

7 Chan AHY, Harrison J, Black PN, Mitchell EA, Foster JM. Using electronic monitoring devices to measure inhaler adherence: a practical guide for clinicians. J. Allergy Clin. Immunol. Pract. 3, 335-349 (2015).

8 Seheult JN, O'Connell P, Tee KC et al. The acoustic features of inhalation can be used to quantify aerosol delivery from a DiskusTM dry powder inhaler. Pharm. Res. 31, 2735-2774 (2014).

9 Kirby SY, Zhu CQ, Kerwin EM, Stanford RH, Georges G. A preference study of two placebo dry powder inhalers in adults with COPD: Ellipta ${ }^{\circledR}$ dry powder inhaler (DPI) versus DISKUS ${ }^{\circledR}$ DPI. COPD 13, 167-75 (2016).

10 Gillette C, Rockich-Winston N, Kuhn JA, Flesher S, Shepherd M. Inhaler technique in children with asthma: A systematic review. Acad. Pediatr. doi:10.1016/j. acap.2016.04.006 (2016) (Epub ahead of print).

- A comprehensive review describing the prevalence of correct inhaler use, educational interventions associated with improved inhaler technique and related outcomes in asthmatic children.
11 Cochrane MG, Bala MV, Downs KE et al. Inhaled corticosteroids for asthma therapy: patient compliance, devices, and inhalation technique. Chest. 117(2), 542-550 (2000)

12 Sanchis J, Gich I, Pederson S. Systematic review of errors in inhaler use: has patient technique improved over time? Chest doi:10.1016/j.chest.2016.03.041 (2016) (Epub ahead of print).

13 Price D, Bosnic-Antichevich S, Briggs A et al. Inhaler competence in asthma: common errors, barriers to use and recommended solutions. Respir. Med. 107(1), 37-46 (2013).

14 Global Initiative for Asthma. Global strategy for asthma management and prevention: 2016 update. www.ginasthma. org

15 Sleath B, Ayala GX, Gillette C et al. Provider demonstration and assessment of child device technique during pediatric asthma visits. Pediatrics 127(4), 642-648 (2011).

16 Sleath B, Carpenter DM, Ayala GX et al. Communication during pediatric asthma visits and child asthma medication device technique 1 month later. J. Asthma 49(9), 918-925 (2012).

17 De Tratto K, Gomez C, Ryan CJ, Bracken N, Steffan A, Corbridge SJ. Nurses' knowledge of inhaler technique in the inpatient hospital setting. Clin. Nurse Spec. 28(3), 156-160 (2014).

18 Mitchell JP. Addressing the problem of noncompliance with inhalers by design: the 'patient-friendly' approach. Ther. Deliv. 2(10), 1217-1219 (2011)

19 About us. Patient Centered Outcomes Research Institute. www.pcori.org/about-us

20 Woodcock A, Bakerly ND, New JP et al. The Salford Lung Study protocol: a pragmatic, randomized phase III real-world effectivenss trial in asthma. BMC Pulm. Med. 15, doi:10.1186/s12890-015-0150-8 (2015) (Epub ahead of print).

-. An excellent study describing a unique, real-world clinical trial that evaluates a prelicensed inhaler medication. 
